\title{
PARCELAMENTO DA ADUBAÇÃO NPK EM ABACAXIZEIRO ${ }^{1}$
}

\author{
LUIZ ANTONIO JUNQUEIRA TEIXEIRA², ADEMAR SPIRONELLO ${ }^{3}$, \\ PEDRO ROBERTO FURLANI ${ }^{4}$, JOSÉ MARIA MONTEIRO SIGRIST ${ }^{5}$
}

\begin{abstract}
RESUMO - Um experimento foi desenvolvido em Agudos (SP), num Argissolo Vermelho-Amarelo, com o objetivo de avaliar o efeito do parcelamento da adubação NPK em abacaxizeiro 'Smooth Cayenne'. Foram estudados os seguintes esquemas de fracionamento da adubação NPK: T1 (testemunha) - N e K parcelados em quatro aplicações ( $60 \mathrm{~kg} \mathrm{ha}^{-1}$ de N e de $\mathrm{K}_{2} \mathrm{O}$ em jun/95; 120, em nov/95; 250, em jan/96 e 120, em mar/96); T2 - N e K parcelados em quatro aplicações $\left(60 \mathrm{~kg} \mathrm{ha}^{-1}\right.$ de N e de $\mathrm{K}_{2} \mathrm{O}$ em jun/95; 120 , em nov/95; 160, em jan/ 96 e 210, em mar/96); T3 - N e K parcelados em três aplicações (90 kg ha ${ }^{-1}$ de $\mathrm{N}$ e de $\mathrm{K}_{2} \mathrm{O}$ em jun/95; 180, em nov/95 e 280, em jan/96); $\mathrm{T} 4$ - N e K parcelados em cinco aplicações $\left(60 \mathrm{~kg} \mathrm{ha}^{-1}\right.$ de $\mathrm{N}$ e de $\mathrm{K}_{2} \mathrm{O}$ em jun/95; 110, em nov/95; 160, em jan/96; 110, em mar/96 e 110, em maio/96); T5 - diferiu do T1 pelo número maior de aplicações de K (cinco) e, do T4 pelo menor número de aplicações de $\mathrm{N}$ (quatro); nesses cinco tratamentos (T1 a T5), todo o P foi aplicado no plantio (maio/95); T6 - N e K parcelados como no T1 e P em duas aplicações (50\% no plantio e $50 \%$ em jan/96). Os frutos, colhidos 21 meses após o plantio, tiveram sua massa média e qualidade influenciadas pela forma de parcelamento da adubação com $\mathrm{N}$ e K; de outro modo, o fracionamento da adubação fosfatada não influenciou a produção. O parcelamento com aplicação mais tardia de N (cinco aplicações, até 12 meses após o plantio-T4) aumentou a produção, contudo, teve efeito negativo sobre o teor de sólidos solúveis dos frutos.
\end{abstract}

Termos para indexação: abacaxi, Ananas comosus (L.) Merril, fertilizantes, qualidade de frutos.

\section{SPLIT APPLICATION OF NPK FERTILIZERS ON PINEAPPLE}

\begin{abstract}
A field experiment was carried out on an Alfisol in São Paulo State, Brazil, with the objective of investigating the effects of split application of NPK fertilizer on pineapple ('Smooth Cayenne') yield and fruit quality. Six patterns of split application of fertilizers were tested as follows: $\mathrm{T} 1$ (control) $-\mathrm{N}$ and $\mathrm{K}$ rates split in four applications $\left(60 \mathrm{~kg} \mathrm{ha}^{-1}\right.$ of N and $\mathrm{K}_{2} \mathrm{O}$ in Jun/95; $120 \mathrm{~kg} \mathrm{ha}^{-1}$ of N and $\mathrm{K}_{2} \mathrm{O}$ in Nov/95; $250 \mathrm{~kg} \mathrm{ha}^{-1}$ of N and $\mathrm{K}_{2} \mathrm{O}$ in Jan/96 and $120 \mathrm{~kg} \mathrm{ha}^{-1}$ of $\mathrm{N}$ and $\mathrm{K}_{2} \mathrm{O}$ in Mar/96); $\mathrm{T} 2-\mathrm{N}$ and $\mathrm{K}$ rates split in four applications $\left(60 \mathrm{~kg} \mathrm{ha}^{-1}\right.$ of $\mathrm{N}$ and $\mathrm{K}_{2} \mathrm{O}$ in Jun$/ 95 ; 120 \mathrm{~kg} \mathrm{ha}^{-1}$ of N and $\mathrm{K}_{2} \mathrm{O}$ in Nov/95; $160 \mathrm{~kg} \mathrm{ha}^{-1}$ of $\mathrm{N}$ and $\mathrm{K}_{2} \mathrm{O}$ in Jan $/ 96$ and $210 \mathrm{~kg} \mathrm{ha}^{-1}$ of N and $\mathrm{K}_{2} \mathrm{O}$ in Mar/96); T3 - $\mathrm{N}$ and $\mathrm{K}$ rates split in three applications $\left(90 \mathrm{~kg} \mathrm{ha}^{-1}\right.$ of $\mathrm{N}$ and $\mathrm{K}_{2} \mathrm{O}$ in Jun/95; $180 \mathrm{~kg} \mathrm{ha}^{-1}$ of N and $\mathrm{K}_{2} \mathrm{O}$ in Nov/95 and 280 $\mathrm{kg} \mathrm{ha}^{-1}$ of $\mathrm{N}$ and $\mathrm{K}_{2} \mathrm{O}$ in Jan/96); $44-\mathrm{N}$ and $\mathrm{K}$ split in five applications $\left(60 \mathrm{~kg} \mathrm{ha}^{-1}\right.$ of $\mathrm{N}$ and $\mathrm{K}_{2} \mathrm{O}$ in Jun/95; $110 \mathrm{~kg} \mathrm{ha}^{-1}$ of N and $\mathrm{K}_{2} \mathrm{O}$ in Nov/95; $160 \mathrm{~kg} \mathrm{ha}^{-1}$ of $\mathrm{N}_{\text {and }} \mathrm{K}_{2} \mathrm{O}$ in Jan/96; $110 \mathrm{~kg} \mathrm{ha}^{-1}$ of $\mathrm{N}$ and $\mathrm{K}_{2} \mathrm{O}$ in Mar/96 and $110 \mathrm{~kg} \mathrm{ha}^{-1}$ of N and $\mathrm{K}_{2} \mathrm{O}$ in May/96); T5 - differed from $\mathrm{T} 1$ due to five applications of N; all P fertilizer was applied at planting (mai/95) in these treatments (T1 to T5); T6 - differed from T1 due to split application of $\mathrm{P}(50 \%$ at planting and $50 \%$ in Jan/96). Fruit weight and quality were influenced by split application of $\mathrm{N}$ and K. Differently, split application of $\mathrm{P}$ has no effect on fruit production. The split of $\mathrm{N}$ rate in five applications produced heavier fruits, but the effect of late application of $\mathrm{N}$ on fruit quality was negative due to a decrease of soluble solids content.
\end{abstract}

Index terms: Ananas comosus (L.) Merril, fruit quality.

\section{INTRODUÇÃO}

A produção de abacaxi no Brasil é superior a 1,5 milhão de toneladas/ano (Nehmi et al., 1999), a qual coloca o País entre os três maiores produtores mundiais. A despeito da importância econômica da cultura, a experimentação sobre adubação de abacaxizeiro é pequena no Brasil e, ainda menor, no Estado de São Paulo.

A cultura é relativamente exigente em nutrientes. Segundo Hiroce et al. (1977), são extraídos aproximadamente $350 \mathrm{~kg} \mathrm{ha}^{-1}$ de N, $30 \mathrm{~kg} \mathrm{ha}^{-1}$ de P e $500 \mathrm{~kg} \mathrm{ha}^{-1}$ de $\mathrm{K}$ em cultivos com 50.000 plantas ha $^{-1}$. Paralelo a essa exigência, tem-se que o ciclo de produção pode durar mais de 20 meses, exigindo que a aplicação de fertilizantes seja parcelada. O parcelamento da adubação com $\mathrm{N}$ e $\mathrm{K}$ possibilita fornecer esses nutrientes de acordo com as exigências da planta, minimizando, especialmente, as perdas por lixiviação (Lacoeuilhe, 1978; Lacoeuilhe et al., 1978). Para Giacomelli \& Py (1981). O fracionamento das doses de adubos a serem aplicadas em abacaxizeiro aumentaria a eficiência das adubações.

Em São Paulo, recomenda-se a aplicação de 300 a 600 $\mathrm{kg} \mathrm{ha}^{-1}$ de N, conforme a produtividade esperada, 40 a $140 \mathrm{~kg}$ ha ${ }^{1}$ de $\mathrm{P}_{2} \mathrm{O}_{5}$ e 100 a $600 \mathrm{~kg} \mathrm{ha}^{-1}$ de $\mathrm{K}_{2} \mathrm{O}$ de acordo com resultados de análise de solo e meta de produtividade para o local (Spironello \& Furlani, 1996). É prescrito, também, que a adubação nitrogenada e potássica (plantios de março/abril) seja parcelada em quatro aplicações ( $10 \%$ em abril-maio, $20 \%$ em novembro, $40 \%$ em janeiro e 30\% em março-abril). Num experimento realizado em condições

\footnotetext{
1 (Trabalho 089/2001). Recebido: 20/04/2001. Aceito para publicação: 08/02/2002.

2 Pesquisador Científico do Centro de Fruticultura/IAC. Cx. Postal 28. 13001-970, Campinas, SP. teixeira@iac.br.

3 Pesquisador Científico Voluntário do Centro de Genética, Biologia Molecular e Fitoquímica/IAC.

4 Pesquisador Científico do Centro de Solos e Recursos Agroambientais/IAC

5 Pesquisador Científico do Centro de Tecnologia de Hortifrutícolas/ITAL, Campinas, SP.
} 
de cultivo semelhantes às deste trabalho, Spironello et al. (1998) constataram incrementos de produtividade em resposta à aplicação de N e K. Entretanto, o aumento na dose de $\mathrm{N}$ causou diminuição no teor de sólidos solúveis e na acidez dos frutos.

O objetivo deste trabalho foi comparar esquemas de parcelamento da adubação com N, P e K em abacaxizeiro, estimando seus efeitos qualitativos e quantitativos sobre a produção de frutos.

\section{MATERIAL E MÉTODOS}

O experimento foi desenvolvido em Agudos (SP), num Argissolo Vermelho-Amarelo, com textura média, em condições de cultivo típicas dessa região, que é uma das mais importantes produtoras do Estado. O clima é mesotérmico de inverno seco (Cwa-Köppen). Em amostragem anterior à instalação do experimento, foram obtidos os seguintes valores médios para alguns atributos químicos do solo: matéria orgânica $=17 \mathrm{~g} \mathrm{~kg}^{-1}$; $\mathrm{pH}\left(\mathrm{CaCl}_{2} 0,01 \mathrm{~mol} \mathrm{~L}^{-1}\right)=4,1 ; \mathrm{P}($ resina $)=8 \mathrm{mg} \mathrm{dm}^{-3} ; \mathrm{K}=7,5$ $\mathrm{mmol}_{\mathrm{c}} \mathrm{dm}^{-3} ; \mathrm{Ca}=7 \mathrm{mmol}_{\mathrm{c}} \mathrm{dm}^{-3} ; \mathrm{Mg}=3 \mathrm{mmol}_{\mathrm{c}} \mathrm{dm}^{-3} ; \mathrm{H}+\mathrm{Al}=31$ $\mathrm{mmol}_{\mathrm{c}} \mathrm{dm}^{-3} \mathrm{e}$ saturação por bases $=27 \%$, segundo metodologia de análise descrita por Raij \& Quaggio (1983).

Empregou-se o delineamento experimental em blocos ao acaso, com seis tratamentos (Tabela 1) e cinco repetições. O esquema de parcelamento do tratamento 1 (testemunha) correspondeu aproximadamente à recomendação de adubação para a região definida por Spironello \& Furlani (1996). As quantidades totais de fertilizantes empregadas em todos os tratamentos foram $550 \mathrm{~kg} \mathrm{ha}^{-1}$ de N (uréia), $550 \mathrm{~kg} \mathrm{ha}^{-1}$ de $\mathrm{K}_{2} \mathrm{O}$ (cloreto de potássio) e $160 \mathrm{~kg} \mathrm{ha}^{-1} \mathrm{de}_{2} \mathrm{O}_{5}$ (superfosfato simples no plantio e superfosfato triplo na útima aplicação do tratamento 6). O P foi aplicado no fundo do sulco na época do plantio; os demais fertilizantes, em cobertura, na base das plantas, procurando-se atingir as axilas das folhas mais velhas. Complementou-se a quantidade de $\mathrm{S}$ no tratamento 6 com $\mathrm{CaSO}_{4}$. Cada parcela constou de seis linhas duplas, com nove plantas por linha, espaçadas de $0,4 \mathrm{~m}$ entre plantas, $0,5 \mathrm{~m}$ entre linhas simples e 1,15 entre linhas duplas (108 plantas). Nas avaliações, foram consideradas 56 plantas $\left(18,5 \mathrm{~m}^{2}\right)$ das quatro linhas centrais.

O experimento foi instalado em 04-05-95, empregandose mudas do tipo "filhote", tamanho médio, da variedade Smooth Cayenne (Havaí ou Bauru). Ocorreu indução floral natural entre 80 e $90 \%$ das plantas; nas restantes, foi aplicado Ethrel (etephon a 21,7\%) na dose de $3 \mathrm{~L} \mathrm{ha}^{-1}$ e uréia na concentração de $20 \mathrm{~g} \mathrm{~L}^{-1}$ de calda.

Antes da emissão da inflorescência, amostraram-se 20 folhas "D" (folha mais nova totalmente desenvolvida) por parcela, tomando-se $20 \mathrm{~cm}$ centrais. As amostras foram processadas e analisadas quanto aos teores de $\mathrm{N}, \mathrm{P}, \mathrm{K}, \mathrm{Ca}, \mathrm{Mg}, \mathrm{B}, \mathrm{Cu}, \mathrm{Fe}, \mathrm{Mn}$ e $\mathrm{Zn}$ de acordo com Bataglia et al. (1983).

A colheita deu-se aos 21,5 meses após o plantio (07/02/ 97), quando os frutos de cada parcela foram contados e pesados. Para estimar a produtividade, os frutos e plantas atacados por fusariose (Fusarium subglutinans) foram descartados. Para as análises químicas da polpa, amostraram-se quatro frutos por parcela. O teor de sólidos solúveis ( ${ }^{\circ}$ Brix) foi estimado com refratômetro manual em amostras das regiões basal, mediana e apical dos frutos. A partir do suco da base e do ápice dos frutos, extraído por centrífuga, fizeram-se as determinações de vitamina C (mg de ácido ascórbico/100 g de amostra) e de acidez titulável (g de ácido cítrico/100 g de amostra), fazendo-se duas medidas por amostra de suco, segundo Carvalho (1990).

Os efeitos dos tratamentos foram avaliados empregando-se o teste $F$. A significância de contrastes entre médias, estabelecidos a priori, foi estimada com o teste $t$ para contrastes. Nas análises de variância e contrastes, empregou-se o módulo GLM (General Linear Models) do SAS, segundo Freund \& Litttell (1981). Foram, também, estabelecidas equações de regressão, relacionando teor foliar de $\mathrm{N}$, teor de sólidos solúveis e massa média dos frutos.

\section{RESULTADOS E DISCUSSÃO}

Os tratamentos de parcelamento da adubação tiveram efeitos significativos sobre a massa média de frutos, produtividade e teor de sólidos solúveis. De outro modo, a distribuição de tamanho dos frutos, acidez e teor de vitamina $\mathrm{C}$ não foi influenciada pelos diversos parcelamentos (Tabela 2).

A massa média de frutos, que variou de 2,55 a $2,84 \mathrm{~kg}$, e a produtividade $\left(77,2\right.$ a $\left.86,1 \mathrm{t} \mathrm{ha}^{-1}\right)$ cresceram com o aumento no número de parcelamentos das adubações. $O$ fracionamento da adubação nitrogenada e potássica em somente três aplicações (junho, novembro e janeiro) mostrou-se inferior quanto à produtividade e à massa média de frutos. $\mathrm{O}$ parcelamento em cinco aplicações, estendendo-se até maio, propiciou produção de frutos mais pesados e produtividade mais elevada do que os tratamentos com três (T3) ou quatro parcelas (contraste T1 vs. T4) (Tabelas 2 e 3 ).

Por meio da análise dos contrastes (Tabela 3 ), observouse que a aplicação mais tardia de potássio não diferiu da testemunha (T1 vs. T5), tanto em relação à quantidade como à qualidade da produção. De outro modo, a adubação nitrogenada tardia fez diminuir o teor de sólidos solúveis dos frutos (T5 vs. T4). Esses resultados divergem do que foi apresentado por Lacoeuilhe (1984). Esse autor afirmou que aplicações mais tardias de $\mathrm{K}$, até mesmo depois da indução floral, seriam úteis para melhorar a qualidade dos frutos. Verificou-se, também, que fracionar a adubação nitrogenada e potássica com aplicações crescentes ao longo do ciclo(T2) não diferiu do tratamento testemunha (T1 vs. T2). O fracionamento da dose de fósforo em duas aplicações (T6), em comparação com a aplicação única no plantio (contraste T1 vs. T6), não teve efeito sobre nenhuma das variáveis estudadas.

Com relação aos teores foliares dos nutrientes analisados, apenas $\mathrm{N}, \mathrm{Ca}$ e $\mathrm{Mg}$ variaram $(p<0,05)$ em função dos diferentes parcelamentos da adubação (Tabelas 4 e 5).

As médias de $\mathrm{N}$ foliar variaram de 9,6 a 13,9 g kg-1 (Tabela 4), estando abaixo da faixa de teores considerada adequada para a cultura, que é de 15 a $17 \mathrm{~g} \mathrm{~kg}^{-1}$, segundo Quaggio et al. (1996). O parcelamento da adubação com aplicação de frações crescentes ao longo do ciclo (T2) e o aumento no número de aplicações (T4), em relação ao tratamento 1, determinaram um significativo incremento no teor foliar de N. Por outro lado, a redução no número de aplicações (T3) diminuiu o teor foliar de $\mathrm{N}$ (Tabela 5). A concentração foliar de P variou de 0,9 a $1,1 \mathrm{~g} \mathrm{~kg}^{-1}$, valores 
○ Massa média de frutos $_{(\mathrm{kg})}=2,18+0,04 \mathrm{~N}$

$\mathrm{R}^{2}=0,27 \quad(p<0,0098)$

- Sólidos solúveis $\left({ }^{\circ}\right.$ Brix $)=15,24-0,16 \mathrm{~N}$

$\mathrm{R}^{2}=0,35 \quad(p<0,0024)$

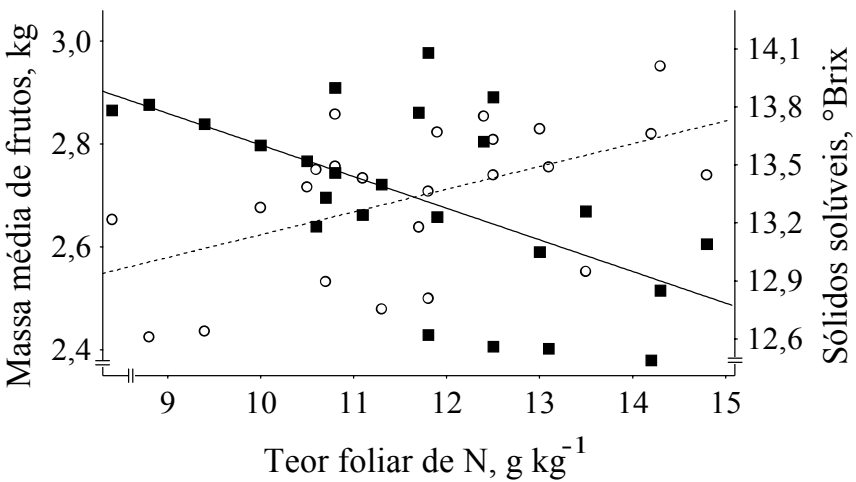

FIGURA 1 - Massa média de frutos e teor de sólidos solúveis em função do teor foliar de nitrogênio em abacaxizeiro.

considerados adequados, segundo Quaggio et al. (1996). O fracionamento da adubação fosfatada em duas aplicações não influenciou o teor foliar de $\mathrm{P}$, ao ser comparado com o tratamento 1 , provavelmente devido às plantas já estarem adequadamente nutridas com esse elemento com o seu fornecimento em dose única no plantio.

A concentração foliar de potássio não variou em função dos tratamentos (Tabela 4), situando-se próximo ao limite inferior da faixa de suficiência (22 a $30 \mathrm{~g} \mathrm{~kg}^{-1}$, segundo Quaggio et al., 1996). Nem mesmo a aplicação mais tardia de K (T4 e T5) aumentou o teor foliar de $\mathrm{K}$ (contrastes T1 vs. T4 e T1 vs. T5 na Tabela 5). Segundo Uexküll (1985), o potássio, além de ser o nutriente absorvido em maior quantidade pela cultura, teria efeito direto sobre a qualidade dos frutos. $\mathrm{O}$ fato de os esquemas de parcelamento não apresentarem efeito sobre o teor foliar de $\mathrm{K}$ ( $p>0,05$, Tabela 4), justificaria, em parte, a ausência de efeitos da aplicação tardia de K sobre a qualidade dos frutos K (contrastes T1 vs. T4 e T1 vs. T5 na Tabela 3).

Os teores foliares de $\mathrm{Ca}$ em todos os tratamentos ficaram abaixo da faixa de suficiência ( 8 a $12 \mathrm{~g} \mathrm{~kg}^{-1}$, segundo Quaggio et al., 1996); para Mg, esses teores foram mais adequados à cultura, situando-se quase sempre acima de $3 \mathrm{~g} \mathrm{~kg}^{-1}$. O parcelamento da adubação com $\mathrm{N}$ e $\mathrm{K}$ teve efeito sobre os teores foliares de $\mathrm{Ca}$ $(p<0,0021)$ e $\mathrm{Mg}(p<0,0759)$. O aumento no número de aplicações (T1 vs. T4) e a adubação potássica mais tardia (T1 vs. T5) causaram incrementos significativos nos teores foliares de $\mathrm{Ca}$ e $\mathrm{Mg}$ (Tabelas 4 e 5).

Na Figura 1, é demonstrado que a massa média de frutos aumentou linearmente com o incremento no teor foliar de $\mathrm{N}$ $(p<0,0098)$. Incrementos de produção em abacaxizeiro relacionados à nutrição nitrogenada foram constatados em vários trabalhos (Bezerra et al., 1981; Obiefuna et al.,1987; Paula et al., 1991; Spironello et al., 1998). Segundo Lacoeuilhe (1975; 1978), o crescimento e desenvolvimento das plantas seriam diretamente dependentes do suprimento de $\mathrm{N}$, e o rendimento de frutos estaria relacionado com essas variáveis. Como o efeito dos tratamentos sobre o teor foliar de $\mathrm{N}$ foi altamente significativo $(p<0,0001$; tabela 4), é possível que os aumentos de produção obtidos com o fracionamento das adubações em maior número de aplicações estejam relacionados à melhoria na nutrição nitrogenada das plantas.

Observa-se, na Figura 1, que o teor de sólidos solúveis apresentou uma resposta linear e negativa ao aumento do teor de $\mathrm{N}$ foliar $(p<0,0024)$. $\mathrm{ON}$, ao propiciar maior crescimento dos frutos, teria afetado o teor de sólidos solúveis (efeito diluição).

TABELA 1 - Esquema dos modos de aplicação de N, P e K (tratamentos) em abacaxizeiro

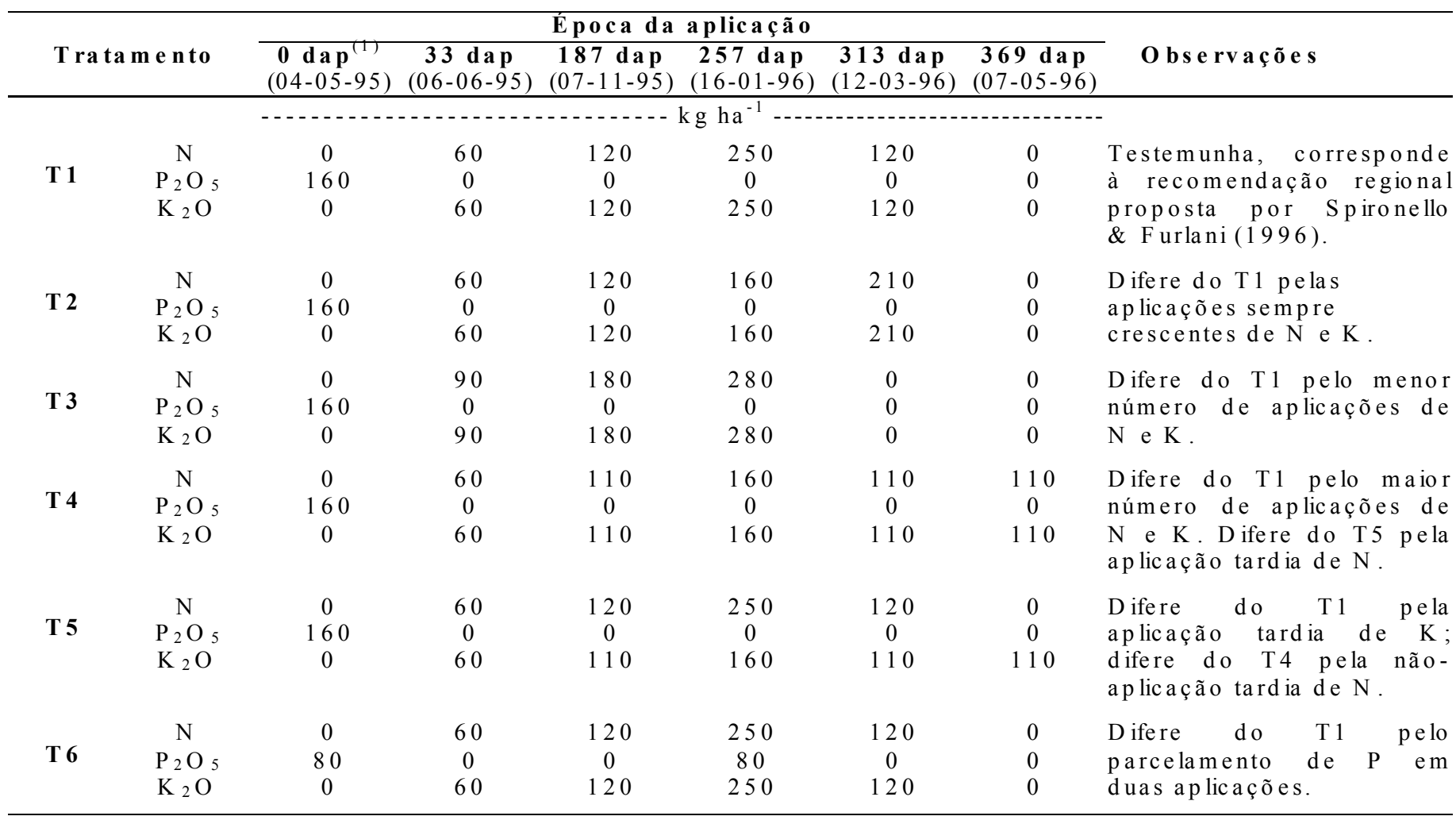

(1) dap = número de dias após o plantio realizado em 04-05-95. 
TABELA 2 - Massa média de frutos, produtividade, distribuição de tamanho dos frutos, sólidos solúveis, acidez e vitamina C; coeficientes de variação e valores $p$ associados aos efeitos dos tratamentos de parcelamento da adubação em abacaxizeiro

\begin{tabular}{|c|c|c|c|c|c|c|c|c|}
\hline \multirow[t]{2}{*}{ Tratame nto $^{(1)}$} & \multirow{2}{*}{$\begin{array}{c}\text { Massa } \\
\text { mé dia de } \\
\text { frutos }\end{array}$} & \multirow{2}{*}{ Produtividade } & \multicolumn{3}{|c|}{$\begin{array}{l}\text { Dis tribuiçãa de tamanho de } \\
\text { frutos }\end{array}$} & \multirow{2}{*}{$\begin{array}{l}\text { Sólidos } \\
\text { solúve is }\end{array}$} & \multirow[t]{2}{*}{$\operatorname{Acide}^{(5)}$} & \multirow[t]{2}{*}{ Vitamina $C^{(6)}$} \\
\hline & & & $\operatorname{Grandes}^{(2)}$ & Médios ${ }^{(3)}$ & Pequenos $^{(4)}$ & & & \\
\hline & $\mathrm{kg}$ & $\mathrm{tha}^{-1}$ & - & -- \% --- & - & ${ }^{\circ}$ Brix & ${\mathrm{g} 100 \mathrm{~g}^{-1}}^{-1}$ & $\mathrm{mg} 100 \mathrm{~g}^{-1}$ \\
\hline 1 & $2,66 \mathrm{ab}$ & $80,7 \mathrm{ab}$ & 75 & 22 & 3 & $13,25 \mathrm{ab}$ & 0,83 & 12,12 \\
\hline 2 & $2,69 \mathrm{ab}$ & $81,4 \mathrm{ab}$ & 75 & 19 & 6 & $13,23 \mathrm{ab}$ & 0,76 & 12,32 \\
\hline 3 & $2,55 \mathrm{~b}$ & $77,2 \mathrm{~b}$ & 69 & 21 & 10 & $13,77 \mathrm{a}$ & 0,82 & 12,39 \\
\hline 4 & $2,84 \mathrm{a}$ & 86,1 a & 76 & 24 & 0 & $12,75 \mathrm{~b}$ & 0,76 & 11,58 \\
\hline 5 & $2,75 \mathrm{ab}$ & $83,2 \mathrm{ab}$ & 82 & 16 & 2 & $13,63 \mathrm{a}$ & 0,83 & 11,97 \\
\hline 6 & $2,76 \mathrm{ab}$ & $83,5 \mathrm{ab}$ & 76 & 17 & 4 & $13,35 \mathrm{ab}$ & 0,80 & 11,74 \\
\hline Média & 2,71 & 82,0 & 76 & 20 & 4 & 13,33 & 0,80 & 12,02 \\
\hline CV $(\%)$ & 4,2 & 4,2 & 17,7 & 70,1 & 166,2 & 2,6 & 7,2 & 5,2 \\
\hline Valor $p^{(7)}$ & 0,0122 & 0,0123 & 0,7210 & 0,9361 & 0,2443 & 0,0116 & 0,3380 & 0,4304 \\
\hline
\end{tabular}

(1) Esquemas de parcelamento (vide tabela 1); ${ }^{(2)}$ Grandes $=$ frutos $>2,6 \mathrm{~kg} ;{ }^{(3)}$ Médios $=$ frutos de 2,0 a 2,6 kg; ${ }^{(4)}$ Pequenos $=$ frutos $<2,0 \mathrm{~kg} ;{ }^{(5)} \mathrm{Acidez}=\mathrm{g}$ de ácido cítrico/100 g de amostra; ${ }^{(6)}$ Vitamina $\mathrm{C}=\mathrm{mg}$ de ácido ascórbico/100 $\mathrm{g}$ de amostra; ${ }^{(7)}$ Valor $p=$ probabilidade de erro tipo I associada ao teste $F$. Valores em negrito: $p<0,05$ ( $F$ significativo a $5 \%$ de probabilidade). Médias seguidas por letras iguais não diferem entre si, pelo teste de Tukey, a $5 \%$ de probabilidade.

TABELA 3 - Contrastes entre os efeitos dos tratamentos de parcelamento da adubação sobre a massa média de frutos, produtividade, distribuição de tamanho dos frutos, sólidos solúveis, acidez e vitamina $\mathrm{C}$ e valores $p$ associados

\begin{tabular}{|c|c|c|c|c|c|c|c|c|}
\hline Contraste & $\begin{array}{c}\text { M assa } \\
\text { média de } \\
\text { frutos }\end{array}$ & Produtividade & \multicolumn{3}{|c|}{$\begin{array}{l}\text { D is tribuição de tamanho de } \\
\text { frutos }\end{array}$} & $\begin{array}{l}\text { Sólidos } \\
\text { solúve is }\end{array}$ & Acide $z$ & Vitam in a $C$ \\
\hline & & & & $\ldots$ V a l & & & & \\
\hline T1 vs. T 3 & 0,1178 & 0,1187 & 0,4763 & 0,8681 & 0,0821 & 0,0488 & 0,9000 & 0,5473 \\
\hline T 1 vs. T 4 & 0,0214 & 0,0213 & 0,8911 & 0,8769 & 0,5476 & 0,0548 & 0,1386 & 0,2434 \\
\hline T 4 vs. T 5 & 0,1950 & 0,1955 & 0,4805 & 0,3716 & 0,6513 & 0,0023 & 0,1149 & 0,3892 \\
\hline
\end{tabular}

(1) Contrastes entre os efeitos dos tratamentos (vide Tabela 1); (2) Valor $p=$ probabilidade de erro tipo I associada ao teste $t$ para o contraste. Valores em negrito: $p<0,05$ (diferença significativa entre os tratamentos do contraste, a $5 \%$ de probabilidade).

TABELA 4 - Teores de nutrientes em amostras de folha $\mathrm{D}$; coeficientes de variação e valores $p$ associados aos efeitos dos tratamentos de parcelamento da adubação em abacaxizeiro

\begin{tabular}{|c|c|c|c|c|c|c|c|c|c|c|}
\hline Tratame nto $^{(1)}$ & $\mathbf{N}$ & $\mathbf{P}$ & $\mathbf{K}$ & $\mathbf{C a}$ & Mg & B & $\mathbf{C u}$ & $\mathbf{F e}$ & Mn & $\mathbf{Z n}$ \\
\hline & \multicolumn{5}{|c|}{ 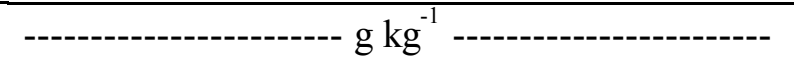 } & \multicolumn{5}{|c|}{----------------------- $\mathrm{mg} \mathrm{kg}^{-1}$------------------- } \\
\hline 1 & $11,1 \mathrm{bc}$ & 0,9 & 22,4 & $3,9 \mathrm{bc}$ & 2,9 & 7 & 3 & 77 & 477 & 7 \\
\hline 2 & $12,9 \mathrm{ab}$ & 1,0 & 22,7 & $4,6 \mathrm{ab}$ & 3,2 & 7 & 3 & 77 & 576 & 8 \\
\hline 3 & $9,6 \mathrm{c}$ & 1,0 & 21,6 & $3,4 \mathrm{c}$ & 2,8 & 8 & 3 & 79 & 419 & 7 \\
\hline 4 & $13,9 \mathrm{a}$ & 1,1 & 22,3 & $5,1 \mathrm{a}$ & 3,5 & 7 & 4 & 80 & 419 & 8 \\
\hline 5 & $11,0 \mathrm{bc}$ & 1,0 & 22,6 & $4,9 a b$ & 3,3 & 8 & 4 & 82 & 549 & 8 \\
\hline 6 & $11,6 \mathrm{bc}$ & 1,0 & 21,9 & 4,1 abc & 3,0 & 8 & 3 & 80 & 515 & 8 \\
\hline Média & 11,7 & 1,0 & 22,3 & 4,3 & 3,1 & 8 & 3 & 79 & 493 & 8 \\
\hline CV (\%) & 7,5 & 8,0 & 4,0 & 11,6 & 11,4 & 17,9 & 23,1 & 10,1 & 26,6 & 13,4 \\
\hline Valor $\boldsymbol{p}^{(2)}$ & 0,0001 & 0,2510 & 0,5095 & 0,0021 & 0,0759 & 0,6520 & 0,5613 & 0,9379 & 0,4418 & 0,8629 \\
\hline
\end{tabular}

(1) Esquemas de parcelamento (Tabela 1); (2) Valor $p=$ probabilidade de erro tipo I associada ao teste $F$. Valores em negrito: $p<0,05$ ( $F$ significativo a $5 \%$ de probabilidade). Médias seguidas por letras iguais não diferem entre si, pelo teste de Tukey, a $5 \%$ de probabilidade. 
TABELA 5 - Contrastes entre os efeitos dos tratamentos de parcelamento da adubação sobre os teores de nutrientes e valores $p$ associados

\begin{tabular}{|c|c|c|c|c|c|c|c|c|c|c|}
\hline Contraste $e^{(1)}$ & $\mathbf{N}$ & $\mathbf{P}$ & $\mathbf{K}$ & $\mathrm{Ca}$ & Mg & B & $\mathbf{C u}$ & $\mathbf{F e}$ & M n & $\mathbf{Z n}$ \\
\hline & & & & & & alor $p^{(2)}$ & & & 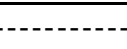 & -------- \\
\hline T 1 vs. T 2 & 0,0131 & 0,4592 & 0,6660 & 0,0772 & 0,2382 & 0,6522 & 0,8870 & 0,9653 & 0,3003 & 0,7101 \\
\hline T 1 vs. T 3 & 0,0269 & 0,1609 & 0,1936 & 0,1777 & 0,6621 & 0,2484 & 0,6039 & 0,7280 & 0,5429 & 0,6853 \\
\hline T 1 vs. T 4 & 0,0004 & 0,0244 & 0,8441 & 0,0036 & 0,0247 & 0,6702 & 0,1827 & 0,5445 & 0,5394 & 0,5228 \\
\hline T 1 vs. T 5 & 0,8434 & 0,0941 & 0,8134 & 0,0188 & 0,0822 & 0,2892 & 0,1974 & 0,3896 & 0,4466 & 0,5228 \\
\hline T 1 vs. T 6 & 0,5048 & 0,2815 & 0,4823 & 0,5977 & 0,5740 & 0,1461 & 0,9245 & 0,5732 & 0,6839 & 0,5898 \\
\hline T 4 vs. T 5 & 0,0003 & 0,4856 & 0,6660 & 0,4294 & 0,5356 & 0,5165 & 0,9622 & 0,7940 & 0,1790 & 0,9999 \\
\hline
\end{tabular}

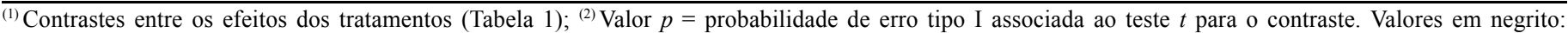
$p<0,05$ (diferença significativa entre os tratamentos do contraste, a $5 \%$ de probabilidade).

Esses resultados são semelhantes aos descritos por Spironello et al. (1998), que observaram que aumentos na massa média de frutos, em resposta à aplicação de $\mathrm{N}$, estiveram associados à diminuição no teor de sólidos solúveis. Outrossim, Martin-Prével (1961) observou que a qualidade dos frutos (coloração, aroma, sabor e resistência ao transporte) melhorava à medida que a relação entre os teores foliares de $\mathrm{K} / \mathrm{N}$ (em porcentagem) se aproximava de três, indicando que eventuais aumentos no teor foliar de $\mathrm{N}$, sem o correspondente incremento de $\mathrm{K}$, poderiam afetar a qualidade da produção.

Aparentemente, a principal diferença entre os esquemas de parcelamento das adubações foi decorrente de alterações na acumulação de nitrogênio nas plantas. Esses efeitos manifestaram-se na qualidade e massa de frutos produzidos. $\mathrm{O}$ parcelamento com cinco aplicações (T4) mostrou-se vantajoso quanto à produtividade, pois o fornecimento de $\mathrm{N}$ até 12 meses após o plantio permitiu que as plantas absorvessem quantidade maior desse nutriente (Tabela 4), com reflexos positivos sobre o tamanho médio dos frutos produzidos (Tabela 2). Entretanto, a maior absorção de $\mathrm{N}$ e o incremento no tamanho dos frutos foram acompanhados por redução no teor de sólidos solúveis (Figura 1, Tabelas 2 e 3 ).

A decisão de qual esquema de parcelamento adotar, depende, portanto, de como a produção será comercializada. Caso o mercado remunere melhor os frutos mais doces, o mais indicado seria evitar a aplicação tardia de nitrogênio. Entretanto, se o preço pago ao produtor depender somente do tamanho médio dos frutos, a melhor opção seria parcelar a dose de nitrogênio em cinco vezes, com aplicações até 12 meses após o plantio.

\section{CONCLUSÕES}

1. A qualidade e massa média dos frutos e os teores foliares de $\mathrm{N}, \mathrm{Ca}$ e Mg foram influenciados pelo parcelamento da adubação nitrogenada e potássica.

2. O parcelamento da adubação fosfatada não influenciou a nutrição e a produção de frutos.

3. A aplicação tardia de N proporcionou aumento na produção; entretanto, o efeito sobre o teor de sólidos solúveis dos frutos foi negativo.

4. A massa média dos frutos aumentou linearmente com o incremento no teor foliar de N; por outro lado, o teor de sólidos solúveis dos frutos apresentou comportamento inverso.

\section{AGRADECIMENTOS}

Aos irmãos Milton e Armando Yoshiura, arrendatários da área (Fazenda Glória) na qual foi instalado o experimento, pelo apoio para a sua execução.

\section{REFERÊNCIAS BIBLIOGRÁFICAS}

BATAGLIA, O.C.; FURLANI, A.M.C.; TEIXEIRA, J.P.F.; FURLANI, P.R.; GALLO, J.R. Métodos de análise química de plantas. Campinas: IAC, 1983. 48p. (Boletim Técnico, 78).

BEZERRA, J.E.F.; MAZZE, U.C.; SANTOS, V.F.; LEDERMAN, I.E. Efeito da adubação nitrogenada, fosfatada e potássica na produção e qualidade do abacaxi cv. 'Smooth Cayenne'. Revista Brasileira de Fruticultura, Recife, v.3, p.1-5, 1981.

CARVALHO, C.R.L. Análises químicas de alimentos. Campinas: Instituto de Tecnologia de Alimentos, 1990. 121p. (Manual técnico)

FREUND, R.J.; LITTELL, R.C. SAS for linear models: a guide to the ANOVA and GLM procedures. Cary: SAS Institute, 1981. $231 \mathrm{p}$

GIACOMELLI, E.J.; PY, C. O abacaxi no Brasil. Campinas: Fundação Cargill, 1981. 101p.

HIROCE, R.; BATAGLIA, O.C.; FURLANI, P.R.; FURLANI, A.M.C.; GIACOMELLI, E.J.; GALLO, J.R. Composição química inorgânica do abacaxizeiro (Ananas comosus 'Cayenne') da região de Bebedouro, SP. Ciência e Cultura, São Paulo, v.29, p.323-6, 1977.

LACOEUILHE, J.J. Ananas. In: MARTIN-PRÉVEL, P.; GAGNARD, J.; GAUTIER, P. (Ed.) L'analyse végétale dans le contrôle de l'alimentation des plantes tempérées et tropicales. Paris: Tec\&Doc, 1984. p.675-94.

LACOEUILHE, J.J. Études sur le contrôle du cycle de l'ananas em Côte d'Ivoire. Fruits, Paris, v.30, p.307-12, 1975.

LACOEUILHE, J.J. La fumure N-K de l'ananas em Côte d'Ivoire. Fruits, Paris, v.33, p.341-8, 1978. 
LACOEUILHE, J.J.; MARCHAL J.; GODEFROY, J. Conservation de la fertilité d'um sol ferrallitique de Basse Côte d'Ivoire cultivé em ananas. Fruits, Paris, v.33, p.241-56, 1978.

MARTIN-PRÉVEL, P. Potassium, calcium et magnésium dans la nutrition de l'ananas em Guinée. III. Influence sur la qualité du fruit. Fruits, Paris, v.16, p.161-80, 1961.

NEHMI, I.M.D.; FERRAZ, J.V.; NEHMI FILHO, V.A.; SILVA, M.L.M. AGRIANUAL 2000: Anuário da Agricultura Brasileira. São Paulo: FNP Consultoria \& Comércio, 1999. 546p.

OBIEFUNA, J.C.; MAJUMDER, P.K.; UCHEAGWU, A.C. Fertilizer rates for increased pineapple production in the tropical ferralitic soils of South Western Nigeria. Fertilizer Research, Dordrecht, v.12, p.99-105, 1987.

PAULA, M.B.; CARVALHO, V.D.; NOGUEIRA, F.D.; SOUZA, L.F.S. Efeito da calagem, potássio e nitrogênio na produção e qualidade do fruto do abacaxizeiro. Pesquisa Agropecuária Brasileira, Brasília, v.26, p.1337-43, 1991.

QUAGGIO, J.A.; RAIJ, B.van; PIZA Jr., C. T. Frutíferas. In: RAIJ, $B$. van et al. (Ed.) Recomendações de adubação e calagem para o Estado de São Paulo. 2.ed. Campinas: IAC, 1996. p.121-5. (Boletim Técnico, 100).
RAIJ, B.van, QUAGGIO, J.A. Métodos de análise química de solo para fins de fertilidade. Campinas: IAC, 1983. 31p. (Boletim Técnico, 81).

SPIRONELLO, A.; QUAGGIO, J.A.; TEIXEIRA, L.A.J.; FURLANI, P.R.; SIGRIST, J.M.M. Adubação NPK do abacaxizeiro 'Smooth Cayenne' na região Central Paulista. In: Congresso Brasileiro de Fruticultura, 15., 1998: Poços de Caldas. Resumos... Lavras: UFLA, 1998. p.26.

SPIRONELLO, A., FURLANI, P.R. Abacaxi. In: RAIJ, B. van et al. (Eds.) Recomendações de adubação e calagem para o Estado de São Paulo. 2.ed. Campinas: IAC, 1996. p.128. (Boletim Técnico, 100).

UEXKÜLL, H.R. von. Potassium nutrition of some tropical plantation crops. In: MUNSON, R.D. (Ed.) Potassium in agriculture. Madison: ASA/CSSA/SSSA, 1985. p.929-54. 